\title{
ANALISA KUALITAS LAYANAN SEBAGAI PENGUKUR LOYALITAS PELANGGAN HOTEL MAJAPAHIT SURABAYA DENGAN PEMASARAN RELASIONAL SEBAGAI VARIABEL INTERVENING
}

\author{
Edwin Japarianto \\ Dosen Program Manajemen Pemasaran Fakultas Ekonomi Universitas Kristen Petra \\ email: edjaparianto@petra.ac.id \\ Poppy Laksmono dan Nur Ainy Khomariyah \\ Alumni Jurusan Manajemen Fakultas Ekonomi, Universitas Kristen Petra, Surabaya
}

\begin{abstract}
Abstrak: Penelitian ini bertujuan untuk meneliti pengaruh kualitas layanan terhadap kesetiaan pelanggan Hotel Majapahit dengan menggunakan variabel pemasaran relasional sebagai variabel intervening. Kualitas layanan ditinjau dari: tangible; reliability, responsiveness, assurance dan empathy. Pemasaran relasional ditinjau dari harmony, acceptance dan participation simplicity. Sedangkan loyalitas pelanggan ditinjau dari say positive things, recommend friend, continue purchasing. Menggunakan regresi dua langkah, hasil penelitian menunjukkan adanya pengaruh langsung dari kualitas layanan terhadap kesetiaan pelanggan serta pengaruh tidak langsung dari kualitas layanan terhadap kesetiaan pelanggan dengan pemasaran relasional sebagai variabel intervening.
\end{abstract}

Kata kunci: kualitas layanan, pemasaran relasional, kesetiaan konsumen

\begin{abstract}
This research aims to investigate the influence of service quality on customer loyaty by using relationship marketing as an intervening variable. Service quality is measured by applying tangible, reliability, responsiveness, assurance and empathy. Relationship marketing is observed from harmony, acceptance dan participation simplicity, while customer loyalty is measured by indicators such as say positive things, recommend friend, and continue purchasing. Using two step regressions, the result indicate that service quality has a direct influence on customer loyalty and indirect effect on customer loyalty with relationship marketing as an invertening variable.
\end{abstract}

Keywords: service cuality, marketingrelasional, customer loyalty

Dahulu fungsi hotel hanya sebagai tempat bermalam bagi konsumen yang melakukan perjalanan bisnis atau wisata dan tidak memiliki relasi di tempat tujuan. Seiring berjalannya waktu, fungsi hotel mengalami peningkatan. Saat ini, seringkali hotel digunakan untuk acara pernikahan, rapat perusahaan, launching untuk produk baru suatu perusahaan dan tak jarang pula hotel digunakan untuk sarana untuk berakhir pekan bagi kalangan masyarakat menengah atas.

Konsumen pada jaman sekarang adalah konsumen yang kritis yang sangat berhati-hati dalam membelanjakan uang. Mereka mempertimbangkan banyak faktor untuk memilih sebuah produk atau jasa termasuk jasa perhotelan. Oleh sebab itu sangat penting bagi Hotel Majapahit Surabaya yang merupakan salah satu penyedia jasa perhotelan di Surabaya untuk merancang konsep pemasaran yang tepat. Sebab hanya perusahaan yang memiliki wawasan tentang konsumen dan konsep pemasaran yang dapat tetap bertahan hidup. Perusahaan tidak terkecuali yang bergerak di bisnis perhotelan dituntut untuk dapat memberikan nilai lebih, dengan cara memperhatikan dan memberikan apa yang diinginkan konsumennya.

Kualitas layanan menjadi hal yang mempengaruhi loyalitas pelanggan. Oleh sebab itu, Hotel Majapahit Surabaya selalu mengadakan evaluasi. Namun pada kenyataannya, dalam pemeliharaan fasilitas Hotel Majapahit masih banyak mengalami kesulitan, dimana hal ini sangat mempengaruhi kualitas jasa Hotel Majapahit Surabaya terhadap konsumennya. Fasilitas fisik yang seharusnya disediakan untuk menunjang kualitas jasa, seringkali justru membuat para konsumen mengeluh karena banyaknya hambatan yang terjadi. Beberapa bentuk keluhan yang disampaikan oleh tamu hotel antara lain adalah pendingin ruangan atau $A C$ yang terdapat di setiap kamar banyak yang mengalami kerusakan, ketersediaan room amenities (seperti: pasta gigi, sabun, shampoo) yang terdapat di setiap kamar mandi seringkali tidak lengkap. Demikian juga dengan 
fasilitas lahan parkir hotel yang hanya mampu menampung tidak lebih dari 400 kendaraan yang dirasakan kurang. Ditambah dengan adanya toilet yang seringkali berbau menyengat akibat kayu-kayu yang sudah tua. Keluhan juga ditujukan bagi karyawan Hotel Majapahit Surabaya yang dinilai masih kurang baik dalam menyampaikan kualitas layanannya, misalnya: tenaga receptionist dalam melayani tamu yang check-in cenderung lambat dan kurangnya jumlah karyawan sehingga menyebabkan pelayanan room service cenderung lama. Berbagai keluhan yang muncul tersebut jelas dapat menganggu kenyamanan konsumen.

Untuk meningkatkan kualitas pelayanannya, Hotel Majapahit Surabaya menerapkan program pemasaran relasional. Penerapan program pemasaran relasional ini diharapkan mampu membuat pelanggan menjadi setia sehingga hubungan yang terjadi tidak hanya hubungan antar penjual dan pembeli, tapi lebih mengarah pada suatu hubungan sebagai mitra. Program pemasaran relasional yang dijalankan Hotel Majapahit Surabaya yaitu privilege card. Dengan memiliki kartu tersebut, pemegang kartu mendapat potongan harga untuk pemakaian fasilitas makan di outlet restoran di Hotel Majapahit Surabaya. Diskon berlaku untuk 1 orang dan diberikan apabila pemegang kartu telah melakukan 18 kali kunjungan makan selama jangka waktu berlakunya kartu. Kartu dapat digunakan baik untuk makan pagi, brunch, siang, malam dan makanan ringan (snack). Selain itu, Hotel Majapahit Surabaya juga memperhatikan pemegang kartu membernya dengan memberikan kartu ucapan selamat ulang tahun bagi yang merayakan di outlet restoran Hotel Majapahit Surabaya dan akan menerima bingkisan sebotol anggur.

Namun demikian, pelaksanaan program pemasaran relasional dirasakan kurang efektif. Masalah yang banyak terjadi adalah banyak tamu hotel yang merupakan pemegang privilege card pada saat menginap, mereka tidak mengetahui adanya manfaat yang dapat mereka peroleh sebagai pemegang privilege card. Selain itu, tidak adanya pemeliharaan hubungan antar pemegang privilege card dengan staf departemen marketing. Dampaknya adalah staf departemen marketing tidak mengetahui apakah pemegang kartu telah menggunakan fasilitas yang tersedia atau belum.

Selain itu dari sisi konsumen, dijumpai kurangnya minat mereka untuk mengikuti program privilege card dikarenakan biaya keanggotaannya yang cukup mahal. Selain itu, kurangnya minat tamu untuk menginap kembali dan merekomendasikan hotel kepada relasinya juga merupakan masalah yang dihadapi oleh pihak hotel.
Berdasarkan latar belakang di atas, permasalahan yang akan dibahas dalam penelitian ini adalah:

1. Apakah ada pengaruh langsung antara kualitas layanan dengan loyalitas konsumen yang dijalankan oleh Hotel Majapahit Surabaya?

2. Apakah ada pengaruh tidak langsung dari kualitas layanan terhadap loyalitas konsumen dengan pemasaran relasional sebagai variabel intervening di Hotel Majapahit Surabaya?

\section{TEORI PENUNJANG}

\section{Pengertian Service}

Menurut Lovelock (1996, p.4) kunci pembedaan jasa dan barang adalah pada kenyataan bahwa konsumen seringkali menerima nilai dari jasa tanpa mendapatkan kepemilikan permanen dari elemen yang berwujud. Dalam banyak contoh, pemasar menawarkan konsumen kesempatan untuk meminjam/menyewa penggunaan dari obyek fisik seperti kamar hotel dan perlengkapan yang tersedia di kamar hotel tersebut.

Seperti yang dikatakan oleh Zeithaml dan Berry (1996) banyak service atau jasa dikemas secara multidimensional atau kompleks, yang terdiri dari banyak elemen-elemen yang berbeda dan dijelaskan bahwa service secara ekstrim adalah perbuatan, proses dan penampilan.

Definisi ini menjelaskan jasa secara murni adalah tidak berwujud. Oleh karena itu jasa murni tidak dapat dilihat, diraba, dipegang ataupun disimpan, sehingga keunggulan dari jasa baru dapat dirasakan oleh konsumen setelah mereka mengkonsumsinya. Dalam hal ini penilaian kualitas sebuah jasa terkait dengan bagaimana kualitas sebuah layanan yang dirasanya nyaman oleh konsumen.

\section{Karakteristik Jasa}

Menurut Kotler (2000, p.660) service memiliki empat karakteristik utama yang membedakan dari suatu barang, yaitu:

\section{Intangibility}

Jasa adalah suatu perbuatan, kinerja (performance). Atau usaha yang hanya bisa dikonsumsi tetapi tidak bisa dimiliki. Jasa bersifat intangible maksudnya tidak dapat dilihat, dirasa, dicium, didengar atau diraba sebelum dibeli dan dikonsumsi. Dengan demikian, seseorang tidak dapat menilai kualitas dari jasa sebelum merasakan/ mengkonsumsi sendiri.

2. Inseparability

Barang biasanya diproduksi, kemudian dijual lalu dikonsumsi. Sedangkan jasa umumnya dijual terlebih dahulu, baru kemudian diproduksi dan dikonsumsi secara bersamaan. Interaksi antara 
penyedia jasa dan pelanggan merupakan ciri khusus dalam pemasaran jasa. Dalam hubungan penyedia jasa dan pelanggan ini, efektivitas individu yang menyampaikan jasa (contactpersonnel) merupakan unsur penting.

3. Variability

Jasa bersifat sangat variabel karena merupakan non-standarized output, artinya banyak variasi bentuk, kualitas, dan jenis, tergantung pada siapa, kapan, dan dimana jasa tersebut dihasilkan. Para pembeli jasa sangat peduli dengan variabilitas yang tinggi ini dan seringkali mereka meminta pendapat orang lain sebelum memutuskan untuk memilih.

4. Perishability

Jasa merupakan komoditas tidak tahan lama dan tidak dapat disimpan. Hal ini tidak menjadi masalah bila permintaannya tetap karena mudah untuk menyiapkan pelayanan untuk permintaan tersebut sebelumnya. Bila permintaan berfluktuasi, berbagai permasalahan muncul berkaitan dengan kapasitas menganggur (saat permintaan sepi) dan pelanggan tidak terlayani dengan resiko mereka kecewa atau beralih ke penyedia jasa lainnya (saat permintaan puncak).

\section{Pengertian Kualitas Layanan}

Definisi umum tentang service quality atau yang seringkali disingkat SERVQUAL dinyatakan oleh Zeithaml (1996) yaitu "a customer's judgment of the overall excellence or superiority of a service". Selanjutnya, SERVQUAL seperti yang dijelaskan oleh Parasuraman, et al (1996) memiliki 5 dimensi sebagai berikut:

a. Tangibles is appearance of the organization's facilities, employees equipment and communication material.

b. Reliability is delivering the promised performance dependably and accurately.

c. Responsiveness is willingness of the organization to provide prompt service and help customer.

d. Assurance (combination of item designed originally to assess competence, credibility, courtesy and security) is ability of the organization's employees to inspire trust and confidence in the organization though their knowledge and courtesy.

e. Empathy (combination of items designed originally to asses, communication and understanding the customer) is personalized attention given to a customer.

\section{Konsep Pemasaran Relasional}

Pemasaran relasional menurut Kotler (2000, p. 13) selain membangun hubungan dengan kosumennya juga dibangun berdasarkan hubungan jangka panjang yang memuaskan dengan pihak-pihak kunci lainnya, seperti: pemasok, penyalur, dan lain-lain guna mempertahankan preferensi dan bisnis jangka panjang mereka. Fungsi utama pemasaran relasional adalah mencakup semua langkah-langkah yang dilakukan perusahaan untuk mengenal dan melayani konsumen mereka yang baik.

Sedangkan menurut Bruhn (2003), pemasaran relasional berhubungan dengan bagaimana sebuah perusahaan mampu membangun keakaraban dengan konsumennya, untuk dapat membangun hubungan yang akrab, maka sebuah perusahaan harus memperhatikan dua dimensi utama, yaitu:

(1) Trust, upaya membangun kepercayaam dengan konsumen, yang terdiri dari tiga attribute yaitu:

1. Harmony, adanya hubungan yang harmonis dengan saling memahami peran baik perusahaan mapun konsmen.

2. Acceptance,adanya hubungan saling menerima berdasar kejelasan dari maksud dan tindakan yang diambil masing-masing pihak.

3. Participation simplicity, kemudahan untuk dapat sealing berhubungan dengan meniadakan batasan-batasan yang bersifat birokratis maupun administrative.

(2) familiarity, membangun situasi dimana seorang konsumen merasa nyaman dalam relationship yang dibangun. terdiri dari tiga attribute yaitu:

1. personal understanding,

2. personal awareness,

3. professional awareness.

\section{Pengertian Loyalitas Pelanggan}

Kotler (2000) mengatakan "the long term success of the a particular brand is not based on the number of consumer who purchase it only once, but on the number who become repeat purchase". Dalam hal ini dapat disimpulkan bahwa konsumen yang loyal tidak diukur dari berapa banyak dia membeli, tapi dari berapa sering dia melakukan pembelian ulang, termasuk disini merekonmendasikan orang lain untuk membeli.

Sedangkan menurut Zeithaml et. al. (1996) tujuan akhir keberhasilan perusahaan menjalin hubungan relasi dengan pelanggannya adalah untuk membentuk loyalitas yang kuat. Indikator dari loyalitas yang kuat adalah:

1. Say positive things, adalah mengatakan hal yang positif tentang produk yang telah dikonsumsi.

2. Recommend friend, adalah merekomendasikan produk yang telah dikonsumsi kepada teman.

3. Continue purchasing, adalah pembelian yang dilakukan secara terus menerus terhadap produk yang telah dikonsumsi. 
Tautan Antar Kualitas Layanan dan Pemasaran Relasional dengan Loyalitas Pelanggan.

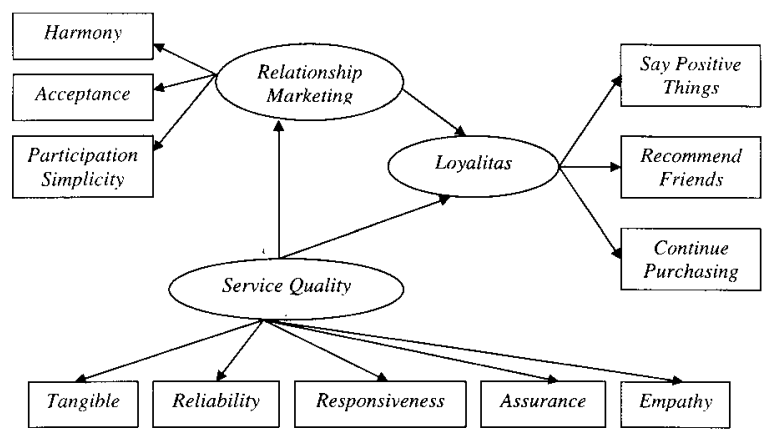

Sumber: Zeithaml (2003, p. 189)

Gambar 1. Hubungan Antara Kualitas Layanan dan Pemasaran Relasional dengan Loyalitas Pelanggan

Dari gambar 1 dapat dijelaskan bahwa indikator kualitas layanan terdiri dari tangibles, reliability, responsiveness, assurance, dan empathy yang berpengaruh pada pemasaran relasional yang memiliki 3 indikator antara lain harmony, acceptance, dan participation simplicity.

Lebih lanjut, kualitas layanan yang baik berpengaruh terhadap loyalitas pelanggan secara langsung. Maka dapat dikatakan bahwa dimensi kualitas layanan yang berupa tangibles, reliability, responsiveness, assurance, dan empathy yang positif berpengaruh langsung dengan dimensi loyalitas pelanggan yaitu mengatakan hal yang positif (say positive things), memberikan rekomendasi kepada orang lain (recommend friend) dan melakukan pembelian terus-menerus (continue purchasing).

Kemudian pemasaran relasional yang kuat dengan dimensinya yang berupa harmony, acceptation, dan participation simplicity yang didukung dengan adanya program privilege card yagn digambarkan berpengaruh langsung terhadap loyalitas pelanggan. Dari hal ini dapat disimpulkan bahwa baik pemasaran relasional berpengaruh langsung terhadap loyalitas pelanggan.

Lebih lanjut, pemasaran relasional dengan dimensinya harmony, acceptance, dan participation simplicity yang didukung dengan adanya privilege card yang digambarkan berpengaruh langsung terhadap loyalitas. Dari hal ini dapat disimpulkan bahwa baik pemasaran relasional berpengaruh langsung terhadap loyalitas pelanggan.

Kualitas layanan dengan dimensinya yang berupa tangible, reliability, responsiveness, assurance,dan empathy digambarkan berpengaruh tidak langsung terhadap loyalitas. Dalam hal ini relationship marketing diposisikan sebagai variabel antara atau intervening karena berhubungan secara tidak langsung antara kualitas layanan dan loyalitas pelanggan. Kualitas layanan yang baik akan menimbulkan pemasaran relasional yang kuat berpengaruh positif pada loyalitas pelanggan.

Dalam penelitian ini, variabel independen adalah kualitas layanan dan variabel dependennya adalah loyalitas pelanggan. Dengan kata lain, kualitas layanan berpengaruh pada loyalitas melalui pemasaran relasional sebagai variabel intervening.

\section{METODOLOGI PENELITIAN}

\section{Jenis Penelitian Dan Gambaran Populasi}

Pada penelitian ini yang dipakai adalah penelitian konklusif eksperimental atau causal research yang merupakan bentuk riset konklusif yang bertujuan untuk memperoleh pengujian yang tepat dalam menarik kesimpulan hubungan sebab akibat antar variabel.

Yang menjadi populasi dalam penelitian ini adalah pelanggan Hotel Majapahit Surabaya yang dalam jangka waktu 1 tahun terakhir melakukan kunjungan sebanyak 1-5 kali dan menggunakan fasilitas pelayanan kamar (menginap di hotel).

\section{Teknik Penarikan Sampel}

Dalam penelitian ini, teknik pengambilan sampel yang digunakan adalah metode non probability sampling dengan purposive sampling. Adapun besarnya sampel yang diambil didasarkan pada rumus sebagai berikut (Hatane, 2003, p. 11), dimana diketahui:

- Jumlah variabel teramati $=\mathrm{p}=25$ item ( item kuesioner )

- Variance dan covariances variabel teramati = $\mathrm{p}(\mathrm{p}+1) / 2=25(25+1) / 2=325$

- Jumlah data $=325$

Sedangkan jumlah parameter yang diestimasi adalah:

- Koefisien regresi (lambda $=\mathrm{L})=25-3=22$ Dikurangi 3 karena dalam standard indikator ada satu L yang difixed atau ditetapkan menjadi 1 untuk standarisasi.

- Error variance $($ delta $=\mathrm{d})=25$

- Variabel laten = 3

- Variance dan covariance $=3(3+1) / 2=6$

- Jumlah parameter $=22+25+6=53$

Sehingga didapatkan hasil akhir jumlah sampel adalah sebagai berikut: 
Jumlah sampel $=$ jumlah data - jumlah parameter

$$
=325-53=272 \text { orang }
$$

\section{Definisi Operasional Variabel Penelitian}

Di dalam penelitian ini terdapat dua variabel independen dan satu variabel dependen.

Variabel independennya adalah:

1. Kualitas layanan, yaitu:

a. Tangibles

Adalah appearance of the organizations facilities, employees, equipment and communication materials. Dalam Hotel Majapahit Surabaya keberwujudan nampak dalam fasilitas fisik di kamar tidur seperti AC, toilet, dan perlengkapan kamar tidur serta room amenities.

b. Reliability

Adalah delivering the promised performance dependability and accurately. Bentuk dari reliability ini adalah kenyamanan konsumen seperti yang dijanjikan, pemesanan kamar yang tepat, dan yang lainnya.

c. Responsiveness

Staf receptionist, room service, dan staf housekeeping Hotel Majapahit Surabaya melayani konsumen sepenuh hati serta membantu kesulitan-kesulitan konsumen.

d. Assurance

Hotel Majapahit Surabaya memberikan jaminan bahwa karyawannya melayani konsumen dengan standart-standart yang sesuai sehingga dapat menimbulkan kepercayaan dan keyakinan konsumen melalui pengetahuan dan kebaikan hati yang tulus.

e. Empathy

Adalah personalized attention given a customer. Bentuk empati dari Hotel Majapahit Surabaya adalah bentuk perhatian khusus kepada setiap pelanggannya.

2. Pemasaran relasional, yaitu;

\section{a. Harmony}

Adalah adanya pemeliharaan hubungan yang terjalin dengan baik melalui program privilege card antara staf departemen marketing Hotel Majapahit Surabaya dengan konsumennya.

b. Acceptance

Konsumen yang bermalam mengetahui adanya program privilege card Hotel Majapahit Surabaya serta memahami keuntungan yang diperolehnya

c. Participation Simplicity

Adalah kemudahan prosedur yang dirasakan oleh konsumen bila berminat menjadi pemegang privilege card.
Sedangkan variabel dependennya adalah:

1. Loyalitas pelanggan, dengan indikator empirik sebagai berikut:

a. Say positive things

Adalah berupa penyampaian kepada orang lain dalam bentuk kata-kata secara positif tentang suatu penyedia jasa, biasanya berupa ulasan, cerita atau uraian pengalaman

b. Recommend friends

Adalah suatu proses yang berujung pada mengajak pihak lain untuk ikut menikmati penyedia jasa tersebut akibat dari pengalaman positif yang dirasakan.

c. Continue purchasing

Adalah sikap untuk membeli ulang terusmenerus oleh konsumen tersebut pada penyedia jasa tertentu sehingga menimbulkan perulangan yang dapat dilandasi dari kesetiaan.

\section{Teknik dan Prosedur Pengumpulan Data}

Data penelitian dikumpulkan dengan cara sebagai berikut:

1. Survei pendahuluan

Penulis bertemu dengan training manager pada tanggal 14 Maret 2006 untuk memperoleh data dan ijin penelitian dan menyebar 300 kuesioner.

2. Studi lapangan melalui wawancara atau interview dengan training manager.

3. Studi kepustakaan

Yaitu data-data atau informasi yang diperoleh melalui buku-buku, literatur, internet yang berhubungan dengan pokok permasalahan yang dibahas. Hal ini dilakukan untuk memperoleh bahan-bahan sebagai pelengkap dan bahan masukan dalam pembauran skripsi.

\section{Teknik Analisis Data}

Dalam penelitian ini akan digunakan alat analisa berupa:

1. Stasistik deskriptif

Merupakan alat statistik yang memberikan gambaran atau deskripsi suatu data yang dilihat dari rata-rata, stantar deviasi, varian, range, kurtosis, skweness (Gozali, 2001, p. 19).

2. Analisa faktor

Analisa faktor mendefinisikan struktur suatu data matrik dan menganalisa faktor yang saling berhubungan antar sejumlah besar variabel. Dengan teknik ini peneliti dapat menentukan dimensi suatu struktur. Jadi analisa faktor ingin meringkas informasi dari variabel asli menjadi suatu set dimensi baru dalam bentuk variabel laten (p.253). 
3. Analisa regresi

Merupakan suatu studi ketergantungan dari variabel dependen terhadap variabel independen, dengan tujuan mengestimasi atau memprediksi rata-rata nilai variabel dependen berdasar nilai variabel independen yang diketahui. Hasil regresi adalah berupa koefisien untuk masing-masing variabel independen, yang akan digunakan untuk memprediksi variabel dependen dalam suatu persamaan (p.81).

\section{ANALISA DAN PEMBAHASAN}

\section{Analisa Profil Responden}

Response rate dalam penelitian ini dapat dikatakan sangat baik mencapai 90,67\% dimana prosentase ini didapat dari jumlah kuesioner yang dibagikan yaitu sebanyak 300 buah dibagi dengan jumlah kuesioner kembali dan valid sebanyak 272 buah (272/300 = 90,67\%).

Sehubungan dengan profil responden, dari survei yang dilakukan, terungkap bahwa sebagian besar responden yang menginap di Hotel Majapahit Surabaya berusia antara 30-34 tahun, berprofesi sebagi pegawai negeri, tujuan responden menginap di Hotel Majapahit adalah untuk berlibur, dengan frekuensi menginap sebanyak 1-3 kali dalam 1 tahun.

\section{Analisa Statistik Deskriptif}

Tabel 1. Penilaian Responden Mengenai Kualitas Layanan

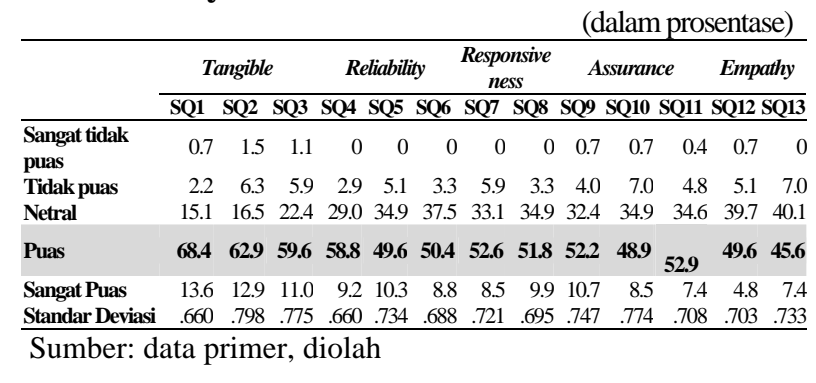

Dari tabel 1 dapat disimpulkan bahwa responden pada prinsipnya telah puas dengan seluruh variabel kualitas layanan hotel. Dimana hal tersebut dapat dilihat lebih dari 50\% tamu hotel memberikan penilaian sangat puas dan puas terhadap kualitas layanan hotel.

Berdasarkan tabel 2 terlihat bahwa responden pada prinsipnya masih belum merasakan manfaat yang muncul dari program pemasaran relasional melalui privilege card yang ditawarkan hotel kepada para pelanggannya. Hal ini dapat dilihat dari penilaian responden yang cenderung netral kecuali pada RM1 (hubungan harmonis antara pihak hotel dan tamu telah terjalin baik).

Tabel 2. Penilaian Responden Mengenai Pemasaran Relasional

\begin{tabular}{lrrrrrr} 
& & \multicolumn{3}{c}{ (dalam prosentase) } \\
\hline & \multicolumn{2}{c}{ Harmony } & \multicolumn{2}{c}{ Acceptance } & \multicolumn{2}{c}{$\begin{array}{c}\text { Participation } \\
\text { Simplicity }\end{array}$} \\
\cline { 2 - 8 } & \multicolumn{1}{c}{ RM1 } & RM2 & RM3 & RM4 & RM5 & RM6 \\
\hline Sangat tidak setuju & 1.5 & 2.9 & 1.5 & 1.1 & 0.4 & 0.7 \\
Tidak setuju & 8.5 & 15.8 & 18.0 & 15.8 & 16.2 & 15.1 \\
Netral & 33.1 & $\mathbf{4 9 . 3}$ & $\mathbf{4 8 . 5}$ & $\mathbf{3 9 . 3}$ & $\mathbf{4 7 . 4}$ & $\mathbf{4 2 . 6}$ \\
Setuju & 51.5 & 28.3 & 30.1 & 37.5 & 30.5 & 26.8 \\
Sangat setuju & 5.5 & 3.7 & 1.8 & 6.3 & 5.5 & 14.7 \\
Standar Deviasi & .787 & .830 & .774 & .853 & .802 & .939 \\
\hline Sumber: data primer, diolah. & & & & &
\end{tabular}

Tabel 3. Penilaian Responden Mengenai Loyalitas Pelanggan

\begin{tabular}{lrrrrrr} 
& & \multicolumn{4}{c}{ (dalam prosentase) } \\
& $\begin{array}{c}\text { Say Positive } \\
\text { Things }\end{array}$ & \multicolumn{2}{c}{$\begin{array}{c}\text { Recommend } \\
\text { Friend }\end{array}$} & \multicolumn{2}{c}{$\begin{array}{c}\text { Continue } \\
\text { Purchasing }\end{array}$} \\
\cline { 2 - 8 } & LOY1 & LOY2 & LOY3 & LOY4 & LOY5 & LOY6 \\
\hline Sangat tidak setuju & 0.7 & 2.2 & 1.1 & 1.5 & 1.1 & 0.7 \\
Tidak setuju & 10.7 & 10.3 & 14.3 & 14.7 & 11.8 & 14.0 \\
Netral & 41.9 & 45.2 & 45.2 & 41.9 & 40.4 & 43.8 \\
Setuju & 38.6 & 31.3 & 25.4 & 30.5 & 28.3 & 30.5 \\
Sangat setuju & 8.1 & 11.0 & 14.0 & 11.4 & 18.4 & 11.0 \\
Standar Deviasi & .816 & .894 & .932 & .918 & .960 & .883 \\
\hline Sting
\end{tabular}

Sumber: data primer, diolah

Berdasarkan tabel 3, terungkap bahwa responden berada pada posisi netral pada loyalitas mereka terhadap Hotel Majapahit.

\section{Analisa Faktor}

Dalam penelitian menggunakan regresi maka diperlukan sebuah variabel sebagai variabel laten, namun dalam pengumpulan data ini terkumpul serangkaian variabel observasi yang harus dikelompokkan menjadi variabel laten. Untuk itu diperlukan teknik analisa faktor dengan tujuan mencari skor faktor yang dapat dijadikan sebagai variabel laten. Adapun hasil pengolahan dari analisa faktor dapat dilihat pada tabel 4 .

\section{Tabel 4. Variabel Kualitas Layanan}

\begin{tabular}{ccccccc}
\hline \multirow{2}{*}{$\begin{array}{c}\text { Compo- } \\
\text { nent }\end{array}$} & \multicolumn{3}{c}{ Initial Eigenvalues } & \multicolumn{3}{c}{$\begin{array}{c}\text { Extraction Sums of } \\
\text { Squared Loadings }\end{array}$} \\
\cline { 2 - 7 } & Total & $\begin{array}{c}\text { \% of } \\
\text { Variance }\end{array}$ & $\begin{array}{c}\text { Cumu- } \\
\text { lative \% }\end{array}$ & Total & $\begin{array}{c}\text { \% of } \\
\text { Variance }\end{array}$ & $\begin{array}{c}\text { Cumula- } \\
\text { tive \% }\end{array}$ \\
\hline 1 & 5.569 & 42.842 & 42.842 & 5.569 & 42.842 & 42.842 \\
2 & 1.536 & 11.814 & 54.656 & 1.536 & 11.814 & 54.656 \\
3 & 1.110 & 8.538 & 63.194 & 1.110 & 8.538 & 63.194 \\
4 & .935 & 7.190 & 70.384 & & & \\
5 & .689 & 5.298 & 75.682 & & & \\
6 & .639 & 4.914 & 80.595 & & & \\
7 & .565 & 4.344 & 84.939 & & & \\
8 & .485 & 3.734 & 88.673 & & & \\
9 & .457 & 3.512 & 92.185 & & & \\
10 & .338 & 2.599 & 94.784 & & & \\
11 & .320 & 2.463 & 97.248 & & & \\
12 & .246 & 1.891 & 99.138 & & & \\
13 & .112 & .862 & 100.000 & & & \\
\hline
\end{tabular}


Extraction Method: Principal Component Analysis. Sumber: kuesioner, diolah.

Dari tabel 4 dapat dilihat bahwa ke-13 variabel kualitas layanan yang ada, dengan menggunakan analisa faktor, ke-13 variabel tersebut diekstrasi menjadi 3 variabel laten. Ketiga variabel laten yang baru terbentuk tersebut diberi nama SQREG1 untuk variabel laten SQ ke-1; SQREG2 untuk variabel laten SQ ke-2; dan SQREG3 untuk variabel laten SQ ke-3.

Tabel 5. Variabel Pemasaran Relasional

\begin{tabular}{ccccccc}
\hline \multirow{2}{*}{$\begin{array}{c}\text { Compo- } \\
\text { nent }\end{array}$} & \multicolumn{2}{c}{ Initial Eigenvalues } & \multicolumn{3}{c}{$\begin{array}{c}\text { Extraction Sums of Squared } \\
\text { Loadings }\end{array}$} \\
\cline { 2 - 6 } & Total & $\begin{array}{c}\text { \% of } \\
\text { Variance }\end{array}$ & $\begin{array}{c}\text { Cumula- } \\
\text { tive \% }\end{array}$ & Total & $\begin{array}{c}\text { \% of } \\
\text { Variance }\end{array}$ & $\begin{array}{c}\text { Cumulative } \\
\text { \% }\end{array}$ \\
\hline 1 & 3.191 & 53.183 & 53.183 & 3.191 & 53.183 & 53.183 \\
2 & .838 & 13.964 & 67.147 & & & \\
3 & .674 & 11.226 & 78.373 & & & \\
4 & .646 & 10.772 & 89.146 & & & \\
5 & .353 & 5.883 & 95.029 & & & \\
6 & .298 & 4.971 & 100.000 & & & \\
\hline
\end{tabular}

Extraction Method: Principal Component Analysis.

Sumber: data primer, diolah

Dari tabel 5 terlihat bahwa ke-6 variabel pemasaran relasional, dengan menggunakan analisa faktor, diekstrasi menjadi satu variabel laten. Variabel laten yang baru terbentuk tersebut diberi nama RMREG.

Tabel 6. Variabel Loyalitas Pelanggan

\begin{tabular}{|c|c|c|c|c|c|c|}
\hline \multirow{2}{*}{$\begin{array}{c}\text { Compo- } \\
\text { nent }\end{array}$} & \multicolumn{3}{|c|}{ Initial Eigenvalues } & \multicolumn{3}{|c|}{$\begin{array}{c}\text { Extraction Sums of Squared } \\
\text { Loadings }\end{array}$} \\
\hline & Total & $\begin{array}{c}\% \text { of } \\
\text { Variance }\end{array}$ & $\begin{array}{l}\text { Cumula- } \\
\text { tive \% }\end{array}$ & Total & $\begin{array}{c}\% \text { of } \\
\text { Variance }\end{array}$ & $\begin{array}{l}\text { Cumula- } \\
\text { tive \% }\end{array}$ \\
\hline 1 & 4.074 & 67.901 & 67.901 & 4.074 & 67.901 & 67.901 \\
\hline 2 & .634 & 10.564 & 78.465 & & & \\
\hline 3 & .491 & 8.185 & 86.650 & & & \\
\hline 4 & .328 & 5.460 & 92.111 & & & \\
\hline 5 & .257 & 4.279 & 96.389 & & & \\
\hline 6 & .217 & 3.611 & 100.000 & & & \\
\hline
\end{tabular}

Dari tabel 6 dapat dilihat bahwa keenam variabel loyalitas pelanggan, dengan menggunakan analisa faktor, dapat diekstrasi satu variabel laten yang baru yang diberi nama LOYREG.

Selanjutnya, variabel-variabel laten yang baru terbentuk (terlihat pada tabel 4-6) yang diperoleh dari analisa faktor tersebut diolah menggunakan teknik analisa regresi dengan variabel dependen $(\mathrm{Y})$ yaitu LOYREG; variabel independen, yaitu SQREG1 (x1); SQREG2 (x2); dan SQREG3 (x3); serta variabel intervening (VI) yaitu RMREG.

\section{Analisa Regresi}

\section{Analisa Regresi 1}

Tabel 7. Model Summary

\begin{tabular}{ccccc}
\hline Model & R & R Square & $\begin{array}{c}\text { Adjusted R } \\
\text { Square }\end{array}$ & $\begin{array}{c}\text { Std. Error of the } \\
\text { Estimate }\end{array}$ \\
\hline 1 & $.450(\mathrm{a})$ & .203 & .194 & .89787530 \\
\hline
\end{tabular}

Sumber: data primer, diolah

Dari tabel 7 dapat dilihat bahwa nilai $R$ square sangat kecil yaitu 0, 203. Hal ini berarti peranan variabel independen dalam mengukur variabel dependen hanya sebesar 20,3\% sedangkan 79,7\% dipengaruhi oleh faktor-faktor lainnya yang tidak diteliti dalam model regresi.

Tabel 8. ANOVA

\begin{tabular}{llrrrrr}
\hline Model & $\begin{array}{c}\text { Sum of } \\
\text { Squares }\end{array}$ & df & $\begin{array}{c}\text { Mean } \\
\text { Square }\end{array}$ & F & Sig. \\
\hline 1 & Regression & 54.944 & 3 & 18.315 & 22.718 & $.000^{\mathrm{a}}$ \\
& Residual & 216.056 & 268 & .806 & & \\
\hline \multicolumn{2}{l}{ Total } & 271.000 & 271 & & & \\
\hline \multicolumn{2}{l}{ Sumber: data primer, diolah }
\end{tabular}

Tabel 8 menunjukkan bahwa bahwa nilai signifikansi $\mathrm{F}$ sebesar $0,000<$ (lebih kecil dari) $\mathrm{p}_{\text {value }}$ sebesar 0,05. Hal tersebut berarti variabel independen secara simultan mampu menjelaskan variabel dependen.

Tabel 9. Coefficients

\begin{tabular}{|c|c|c|c|c|c|c|}
\hline \multirow{2}{*}{\multicolumn{2}{|c|}{ Model }} & \multicolumn{2}{|c|}{$\begin{array}{l}\text { Unstaandarsized } \\
\text { Coefficients }\end{array}$} & \multicolumn{2}{|c|}{$\begin{array}{l}\text { Standardized } \\
\text { Coefficients }\end{array}$} & \multirow[t]{2}{*}{ Sig. } \\
\hline & & B & Std. Error & Beta & $t$ & \\
\hline \multirow[t]{4}{*}{1} & (Constant) & $1.23 \mathrm{E}-0.16$ & .054 & & .000 & 1.000 \\
\hline & SQREG 1 & .437 & .055 & .437 & 8.007 & .000 \\
\hline & SQREG 2 & -.008 & .055 & -.008 & -.143 & .887 \\
\hline & SQREG 3 & .109 & .055 & .109 & 2.006 & .046 \\
\hline
\end{tabular}

Sumber: data primer, diolah

Dari tabel 9 dapat dilihat bahwa nilai signifikansi $t$ adalah sebagai berikut:

1. SQREG $1=0,000<$ (lebih kecil dari) $\mathrm{p}_{\text {value }}$ sebesar 0,05 . Hal ini berarti variabel independen secara parsial mampu menjelaskan variabel dependen.

2. SQREG $2=0,887>$ (lebih besar dari) $p_{\text {value }}$ sebesar 0,05. Hal ini berarti variabel independen secara parsial tidak mampu menjelaskan variabel dependen.

3. SQREG $3=0,046>$ (lebih besar dari) p palue sebesar 0,05 Hal ini berarti variabel independen secara parsial tidak mampu menjelaskan variabel dependen.

\section{Analisa Regresi 2}

\section{Tabel 10. Model Summary}

\begin{tabular}{ccccc}
\hline Model & R & R Square & Adjusted R Squre & Std. Error of the Estimate \\
\hline 1 & $.684^{\mathrm{a}}$ & .467 & .459 & .73535276 \\
\hline Sumber: data primer, diolah & &
\end{tabular}

Dari tabel 10 terlihat bahwa nilai $R$ square kecil yaitu sebesar 0,467 . Hal ini berarti peranan variabel independen dalam mengukur variabel dependen 
hanya $46,7 \%$, sedangkan 53,3\% dipengaruhi oleh faktor-faktor lainnya yang tidak diteliti dalam model regresi.

Tabel 11. ANOVA

\begin{tabular}{llrrrrr}
\hline Model & & $\begin{array}{c}\text { Sum of } \\
\text { Squares }\end{array}$ & df & \multicolumn{1}{c}{$\begin{array}{c}\text { Mean } \\
\text { Square }\end{array}$} & F & Sig. \\
\hline 1 & Regression & 126.621 & 4 & 31.655 & 58.540 & $.000^{\mathrm{a}}$ \\
& Residual & 144.379 & 267 & .541 & & \\
\hline & Total & 271.000 & 271 & & & \\
\hline
\end{tabular}

Sumber: data primer, diolah

Dari tabel 11 dapat dilihat bahwa nilai signifikansi $\mathrm{F}$ sebesar $0,000<$ (lebih kecil dari) p palue sebesar 0,05. Hal tersebut berarti variabel independen secara simultan mampu menjelaskan variabel dependen.

Tabel 12. Coefficients

\begin{tabular}{llrrrrr}
\hline \multirow{2}{*}{ Model } & \multicolumn{2}{c}{$\begin{array}{c}\text { Unstaandarsized } \\
\text { Coefficients }\end{array}$} & \multicolumn{3}{c}{$\begin{array}{c}\text { Standardized } \\
\text { Coefficients }\end{array}$} & \multirow{2}{*}{ Sig. } \\
\cline { 3 - 6 } & & \multicolumn{2}{c}{ B } & Std. Error & Beta & \multicolumn{1}{c}{ t } \\
\hline 1 & (Constant) & $1.75 E-016$ & .054 & & .000 & 1.000 \\
& SQREG 1 &. .387 & .050 & .387 & 7.780 & .000 \\
\hline & SQREG 2 & .113 & .045 & .113 & 2.527 & .012 \\
\hline & SQREG 3 & .056 & .045 & .056 & 1.242 & .215 \\
\hline & RMREG & .402 & .050 & .402 & 8.037 & .000 \\
\hline
\end{tabular}

Sumber: data primer, diolah

Dari tabel 12 dapat dilihat bahwa nilai signifikansi t adalah sebagai berikut:

1. SQREG $1=0,000<$ (lebih kecil dari) $\mathrm{p}_{\text {value }}$ sebesar 0,05 . Hal ini berarti variabel independen secara parsial mampu menjelaskan variabel dependen.

2. SQREG $2=0,012>$ (lebih besar dari) p palue sebesar 0,05. Hal ini berarti variabel independen secara parsial tidak mampu menjelaskan variabel dependen.

3. SQREG $3=0,215>$ (lebih besar dari) p palue sebesar 0,05 hal ini berarti variabel independen secara parsial tidak mampu menjelaskan variabel dependen.

4. $\operatorname{RMREG}=0,000<$ (lebih kecil dari) $\mathrm{p}_{\text {value }}$ sebesar 0,005 . Hal ini berarti variabel independen secara parsial mampu menjelaskan variabel dependen.

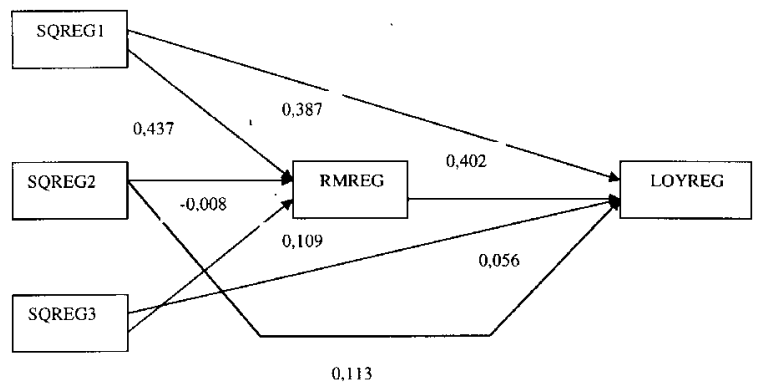

Gambar 2. Model Persamaan Struktural
Selanjutnya, persamaan regresi yang muncul adalah sebagai berikut:

\section{Persamaan 1:}

$$
\begin{aligned}
\text { RMREG }= & 0,437 \text { SQREG1 }-\underset{0,008 \text { SQREG2 + }}{ }(0,000) \quad(0,887) \\
& 0,109 \text { SQREG3 } \\
& (0,046)
\end{aligned}
$$

Persamaan 2 (pengaruh langsung):

$$
\begin{aligned}
\text { LOYREG }= & \underset{ }{0,387 \text { SQREG1 }}+\underset{(0,000)}{0,113 \text { SQREG2 }+}(012) \\
& 0,056 \text { SQREG3 } \\
& (0,215)
\end{aligned}
$$

Persamaan 3 (pengaruh tidak langsung):

$$
\begin{aligned}
& (0,437 \times 0,502) \quad(-0,008 \times 0,402) \quad(0,109 \times 0,402) \\
& \text { LOYREG }=0,176 \text { SQREG1 }-0,003 \text { SQREG2 + 0,044 SQREG3 + } \\
& (0,000) \quad(0,012) \quad(0,215) \\
& \text { 0,402 REREG } \\
& (0,000)
\end{aligned}
$$

Dari persamaan 2 dan persamaan 3 dapat dilihat perbedaan pengaruh langsung variabel independen terhadap variabel dependen, dan pengaruh tidak langsung melalui variabel intervening tidak terlalu signifikan, sehingga variabel intervening tidak terlalu berpengaruh pada variabel dependen.

\section{KESIMPULAN}

Dari analisa deskriptif mengindikasikan bahwa sebagian besar responden cenderung puas pada layanan yang diberikan oleh Hotel Majapahit, serta menilai netral pada penilaian mereka terhadap kinerja program pemasaran relasional yang dijalankan oleh pihak hotel. Selain itu responden juga menilai netral untuk tingkat loyalitas mereka terhadap hotel Majapahit.

Sedangkan hasil analisa regresi dapat dilihat bahwa terdapat pengaruh dari kualitas layanan (SQREG) terhadap loyalitas pelanggan (LOYREG) secara langsung. Selain itu kualitas layanan (SQREG) berpengaruh secara tidak langsung melalui program pemasaran relasional (RMREG) sebagai variabel intervening. Hal ini menyatakan bahwa program pemasaran relasional yang dijalankan oleh pihak hotel tidak mempunyai kontribusi nyata dalam meningkatkan loyalitas pelanggan Hotel Majapahit Surabaya.

\section{DAFTAR PUSTAKA}

Bruhn, M. (2003), Pemasaran relasional: Management of customer relationship, ( $1^{\text {st }}$ edn), New Jersey: Prentice Hall. 
Egan, J. (2004), Pemasaran relasional exploring relational strategies in marketing, ( $1^{\text {st }}$ edn), New Jersey: Prentice Hall.

Hatane, S. (2003), Structural equition modelling dengan lisrel 8.5, Surabaya: Tim Manajemen Sains, Fakultas Ekonomi Universitas Kristen Petra.

Gozali, I. (2005), Analisis multivariate dengan program SPSS, Semarang: Badan Penerbit Universitas Diponegoro.

Kanuk, L. L. (2003), Consumer behavior, $\left(8^{\text {th }}\right.$ edn), Pearson Publisher.

Kotler, P. (2000), Marketing management: Analysis, planning, implementation and control, ( $8^{\text {th }}$ edn), New Jersey: Prentice Hall International.Inc.

Lovelock, C. H, (1996). Service marketing, ( $3^{\text {rd }}$ edn),

Singarimbun, M. (1995), Metode penelitian survai, Jakarta: Gramedia Pustaka Utama.

Sugiyono (2005), Metode penelitian bisnis, (cetakan ke 3), Bandung: CV. Alfabeta.

Umar, H. (1999), Metode penelitian untuk pemasaran, Jakarta: Gramedia Pustaka Utama.

Zeithaml, A. V., Berry. L. L., \& Parasuraman, A. (1996, April). Journal of Marketing, (60), pp. 41-46.

Zeithaml et al., (1996). Measuring the quality of relationship in customer service: An empirical study. European. Journal of Marketing. 